\title{
EDUCAÇÃO EM ENFERMAGEM NO BRASIL: AVANÇOS E RISCOS
}

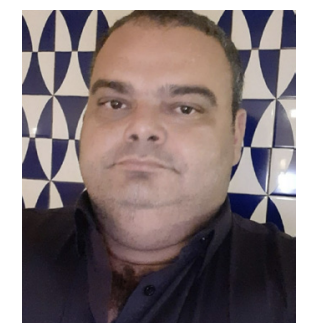

Francisco Rosemiro Guimarães Ximenes Neto Editor Associado da Revista Enfermagem em Foco https://orcid.org/ 0000-0002-7905-9990

A formação universitária em Enfermagem, nas últimas três décadas, tem passado por diversas e significativas mudanças e avanços, tanto na perspectiva epistemológica, dos referenciais teórico-filosóficos a serem utilizados nos projetos pedagógicos e na matriz curricular, quanto na prática educativa com a revisitação das aulas teóricas, assim como nas vivências e estágios.

A institucionalização das Diretrizes Curriculares Nacionais (DCN) foi um desses avanços, que estimulou os cursos de graduação a reformularem seus projetos pedagógicos e currículos, estabelecendo um perfil do formando e as competências educacionais, dentre outros elementos didático-pedagógicos, que vem contribuindo no caso das profissões da saúde, para a mudança paradigmática estabelecida pelo modelo hegemônico de ensino flexneriano.

Outras mudanças importantes têm sido a ampliação da carga horária da graduação em Enfermagem, para no mínimo de quatro mil horas, a integralização em cinco anos e os currículos em tempo integral adotados por muitas Escolas de Enfermagem, que vem oportunizando ao estudante vivenciar mais conteúdos teóricos, estágios e atividades complementares, além do internato no último ano na Atenção Primária à Saúde (APS) e na Clínica Hospitalar, proporcionando um melhor preparo dos formandos para o mercado de trabalho em saúde. Tem crescido também, o número de Escolas de Enfermagem que implementam a associação da tríade - ensino, pesquisa e extensão, durante o processo de formação.

A mudança curricular influenciada pelas demandas e necessidades do Sistema Único de Saúde (SUS), foi um marco importante, permitindo o estudante vivenciar conteúdos e práticas baseados no perfil epidemiológico locorregional e nas políticas sanitárias, levando a transição, ainda que incipiente em muitos cursos, do deslocamento dos estágios da clínica hospitalar, sobretudo para a APS e gestão sanitária.
Com a mudança na episteme dos projetos pedagógicos, vem ocorrendo a introdução de práticas inovadoras de ensino-aprendizagem, em detrimento às tradicionais, por meio de metodologias ativas, com o experimentar de abordagens transformadoras e da aprendizagem significativa. O desenvolvimento de uma cultura de uso das Tecnologias da Informação e Comunicação (TIC) tem se tornado presente, buscando articular as diferentes abordagens pedagógicas de forma crítica e criativa, sem perder o componente da ética. Tais mudanças têm sido fomentadas, pela implementação das DCN e pela importante formação acadêmica do corpo docente e de pesquisadores em programas de pós-graduação Stricto Sensu (Mestrado e Doutorado).

A implantação de diversas políticas de APS, a exemplo da Estratégia Saúde da Família (ESF), levou a ampliação do mercado de serviços de saúde, demandando a necessidade de formação de uma nova força de trabalho, o que influenciou a abertura de cursos em várias áreas, em especial na Enfermagem. Além das políticas de APS, a publicação da Lei de Diretrizes e Bases da Educação (LDB), associada ao liberalismo educacional motivou o atual fenômeno da mercantilização do ensino na saúde, evidenciando um "boom" de Escolas de Enfermagem em todo o país, com a participação majoritária do ensino privado ${ }^{1-2}$. No período de 1991 (ano seguinte da regulamentação do SUS) a 2018, os Cursos de Enfermagem passaram de 106 (61 públicos e 45 privados) para 1.048 (154 públicos e 894 privados), um aumento de $989 \%{ }^{3-4}$.

O ensino de Enfermagem mantém-se em franca expansão na iniciativa privada, enquanto que no setor público apresenta discreta redução do número de cursos (4,5\%). A Enfermagem em 2018 registrou 313.237 matrículas, estando entre os dez maiores cursos de graduação em números de matrículas, atrás somente dos cursos de Direito, Pedagogia, Administração, Contabilidade e Engenharia Civil4.

A liberalização do ensino universitário e sua expansão na iniciativa privada, motivou a disseminação do Ensino

\footnotetext{
${ }^{1}$ Enfermeiro, Professor e Pesquisador do Curso de Enfermagem e do Mestrado Profissional em Saúde da Família da Universidade Estadual Vale do Acaraú (UVA) e do Mestrado Acadêmico em Saúde da Familia da Universidade Federal do Ceará (UFC).Coordenador da Câmara Técnica de Educação e Pesquisa (CTEP) do Conselho Federal de Enfermagem (COFEN). E-mail: rosemironeto@gmail.com
} 
a Distância (EaD) na Enfermagem. O Censo da Educação Superior de 2018 aponta sete cursos de Enfermagem na modalidade EaD, sendo quatro em universidades e três em centros universitários, ofertando 66.402 vagas, com 75.460 candidatos inscritos, registrando 22.325 ingressos e 94 concluintes ${ }^{4}$

Recentemente, o Ministério da Educação (MEC), publicou a Portaria № 2.117, de 6 de dezembro de 2019, que autoriza as Instituições de Ensino Superior (IES) a ampliarem para até o limite de 40\% a carga horária de EaD, na organização pedagógica e curricular em todos os cursos de graduação presenciais, com exceção do Curso de Medicina. Tal decisão afeta a formação em Enfermagem, pois parte das quatro mil horas e a integralização de cinco anos, pode-se resumir a três anos de aulas presenciais e pargos estágios ${ }^{5}$.

A decisão do MEC em ampliar a carga horária EaD no cursos presenciais ou mesmo permitir a existência de cursos totalmente EaD na Enfermagem, afeta o processo formativo e a qualidade da assistência que será prestada à população. Sabemos que o estudante ao vivenciar um curso em cinco anos, de modo integral, apresenta sérias dificuldades e fragilidades para atuar, sobretudo, na APS no cuidado às famílias, sujeitos e comunidades por conta da diversidade de conhecimentos e do escopo de práticas que são demandados.

O EaD na Enfermagem e na Saúde, representa um risco para as profissões e, sobretudo, para a população brasileira que fica vulnerável ao ser assistida por profissionais com formação questionável, em cursos que não apresentam critérios mínimos de qualidade $\mathrm{e}^{\mathrm{l}-2}$
O estudante para que possa ter um processo formativo de qualidade e que dê respostas à sua clientela futura, necessita de vivências e estágios na realidade do SUS, em comunidades, lares, centros de saúde, clínicas especializadas hospitais gerais e especializados para o desenvolvimento de expertise da práxis clínica, além de outros espaços como no Gerenciamento de Serviços de Saúde e na Gestão Sanitária, que fomentem a produção de conhecimento em Enfermagem, numa perspectiva da subjetividade humana e do cuidado holístico humanizado nos processos de nascer, viver, adoecer e morrer.

O Sistema Conselho Federal de Enfermagem (COFEN)/Conselhos Regionais e demais entidades têm a compressão que a formação em Saúde e Enfermagem deve ser na modalidade presencial, para evitar riscos à população brasileira, não fragilizar os princípios do SUS e ferir os Direitos Humanos.

Este número da Revista Enfermagem em Foco congrega trinta artigos, que em sua maioria versam sobre a temática da Educação em diversas vertentes, desde a formação universitária, extensão, estágio, condições de formação dos estudantes, expansão dos cursos de graduação, currículo, processo ensino-aprendizagem, educação permanente, educação na saúde, residência multiprofissional, tecnologias educacionais, dentre outros.

Deleitem-se com os artigos e uma boa leitura!

Descritores: Enfermagem; Educação em Enfermagem.

Descriptors: Nursing; Education, Nursing.

Descriptores: Enfermería; Educación en Enfermería.

\section{REFERÊNCIAS}

1. Ximenes Neto FRG, Lopes Neto D, Cunha ICKO, Ribeiro MA, Freire NP, Kalinowski CE et al. Reflexões sobre a formação em Enfermagem no Brasil a partir da regulamentação do Sistema Único de Saúde. Ciênc. saúde coletiva [Internet]. 2020 Jan [cited 2020 Mar 11]: 25(1): 37-46. Available from: http://www.scielo.br/scielo.php?script=sci_arttext\&pi$d=\$ 1413-81232020000100037$ lng=pt. Epub 20-Dez-2019. https://doi. org/10.1590/1413-81232020251.27702019.

2. Machado MH, Ximenes Neto FRG. Gestão da Educação e do Trabatho em Saúde no SUS: trinta anos de avanços e desafios. Ciênc. saúde coletiva [Internet]. 2018 Jun [cited 2020 Mar 11]; 23(6): 1971-1979. Available from: http://www.scielo.br/scielo.php?script=sci_arttextEpid=S1413-81232018000601971\&lng=pt. https://doi.org/10.1590/141381232018236.06682018 .

3. Vieira ALS, Moyses NMN. Trajetória da graduação das catorze profis- sões de saúde no Brasil. Saúde debate [Internet]. 2017 [cited 2020 Mar 11]; 41(113):401-414. Available from: <http://www.scielo.br/scielo.php?script=sci_arttext\&pid=S0103-11042017000200401\&lng=pt>

4. Ministério da Educação (BR). Instituto Nacional de Estudos e Pesquisas Educacionais Anísio Teixeira (INEP). Censo da Educação Superior 2018 - Divulgação dos principais resultados. [Internet]. 2019 [cited 2020 Mar 11]. Available from: < http://portal.inep.gov.br/web/guest/sinopses-estatisticas-da-educacao-superior>

5. Ministério da Educação (BR). Portaria № 2.117, de 6/12/2019. Dispõe sobre a oferta de carga horária na modalidade de Ensino a Distância - EaD em cursos de graduação presenciais ofertados por Instituições de Educação Superior - IES pertencentes ao Sistema Federal de Ensino. DOU [Internet]. 2019 Dez 11 [cited 2020 Mar 11]. Available from: https://www.jusbrasil.com.br/ diarios/275937634/dou-secao-1-11-12-2019-pg-131. 